\title{
An Immunocompromised Murine Model of Chronic Bartonella Infection
}

\author{
Lucius Chiaraviglio, ${ }^{*}$ Scott Duong, ${ }^{*}$ \\ Daniel A. Brown, ${ }^{*}$ Richard J. Birtles, ${ }^{\dagger}$ \\ and James E. Kirby* \\ From the Department of Pathology,* Beth Israel Deaconess \\ Medical Center, Boston, Massachusetts; and the Disease Ecology \\ Group, ${ }^{\dagger}$ Centre for Comparative Infectious Diseases, Faculty of \\ Veterinary Science, University of Liverpool, Liverpool, United \\ Kingdom
}

Bartonella are ubiquitous Gram-negative pathogens that cause chronic blood stream infections in mammals. Two species most often responsible for human infection, $B$. benselae and $B$. quintana, cause prolonged febrile illness in immunocompetent hosts, known as cat scratch disease and trench fever, respectively. Fascinatingly, in immunocompromised hosts, these organisms also induce new blood vessel formation leading to the formation of angioproliferative tumors, a disease process named bacillary angiomatosis. In addition, they cause an endothelial-lined cystic disease in the liver known as bacillary peliosis. Unfortunately, there are as yet no completely satisfying small animal models for exploring these unique human pathologies, as neither species appears able to sustain infection in small animal models. Therefore, we investigated the potential use of other Bartonella species for their ability to recapitulate human pathologies in an immunodeficient murine host. Here, we demonstrate the ability of Bartonella taylo$r i$ to cause chronic infection in SCID/BEIGE mice. In this model, Bartonella grows in extracellular aggregates, embedded within collagen matrix, similar to previous observations in cat scratch disease, bacillary peliosis, and bacillary angiomatosis. Interestingly, despite overwhelming infection later in disease, evidence for significant intracellular replication in endothelial or other cell types was not evident. We believe that this new model will provide an important new tool for investigation of Bartonella-host interaction. (AmJ Pathol 2010, 176:2753-2763; DOI: 10.2353/ajpath.2010.090862)

Bartonella causes chronic systemic infections in animals as diverse as humans, ${ }^{1}$ whales, ${ }^{2}$ kangaroos, ${ }^{3}$ bats, ${ }^{4}$ cats, voles, ${ }^{5}$ deer, ${ }^{6}$ and turtles. ${ }^{7}$ Remarkably, prevalence of infection exceeds $50 \%$ in populations of various mammals (prairie dogs, ${ }^{8}$ rodents, ${ }^{9}$ deer, ${ }^{10}$ and cattle ${ }^{11}$ ) from around the world including the United States, making it perhaps the most common cause of chronic bacterial bloodstream infection. Bartonella are generally spread among these hosts by blood sucking vectors (e.g., fleas, mites, ticks, midges, and flies). Humans in turn become infected through contact with infected animals or arthropods.

In humans, Bartonella henselae-the species most often implicated in human disease-causes a prolonged febrile illness, known as cat scratch disease, associated with fever and swollen lymph nodes. ${ }^{12}$ Some patients go on to develop infections of the brain (encephalopathy) and retina. Similarly, Bartonella quintana causes a prolonged febrile illness, primarily in the homeless. During World War I, it was responsible for a debilitating epidemic among soldiers known as trench fever. Both organisms also cause heart valve infection (endocarditis), which may require heart valve replacement. Several other Bartonella species are also now increasingly recognized as causes of human blood stream infection and endocarditis. Seroprevalence in humans for Bartonella henselae alone is estimated to be 3 to $5 \% .{ }^{13}$ With more robust molecular methods it is now clear that many other Bartonella species in addition to $B$. henselae infect people. For example, a recent study found that $5 \%$ of patients from the Southwestern United States with unexplained chronic fever and fatigue show seroconversion to Bartonella antigens from previously unidentified species found in local rodent populations. ${ }^{14}$

Fascinatingly, in immunocompromised patients, especially those with AIDS, $B$. henselae and quintana cause a disease known as bacillary angiomatosis. ${ }^{12}$ In this illness, organisms induce new blood vessel formation (i.e., angiogenesis). These proliferating blood vessels form benign tumor masses. Bartonella bacilliformis (geographically lim-

\footnotetext{
Supported by an American Heart Association Grant-In-Aid (to J.E.K.).

Accepted for publication January 26, 2010.

Current address for S.D.: North Shore-Long Island Jewish Health System Laboratories, Lake Success, NY.

Address reprint requests to James E. Kirby, M.D., Division of Experimental Pathology, Beth Israel Deaconess Medical Center, 330 Brookline Ave - YA309, Boston, MA 02215. E-mail: jekirby@bidmc.harvard.edu.
} 
ited to South America), in contrast, causes angiogenesis in previously immunocompetent human hosts. In acute disease, those infected develop profoundly low blood cell counts and often die from secondary, opportunistic infections. In the second stage of disease, angioproliferative tumors cover the entire body, a disease known as verruga peruana. ${ }^{15}$ In both bacillary angiomatosis and verruga peruana, angioproliferative tumors only occur in association with large local concentrations of organisms in tissues and regress with antibiotic treatment. A related disease process, bacillary peliosis, occurs primarily in the livers of $B$. henselae-infected immunocompromised patients. Bacillary peliosis is characterized by the development of dilated endothelial-lined cysts with large quantities of organisms within the surrounding extracellular matrix. ${ }^{16}$ This disease process has been interpreted as another form of abnormal vascular proliferation.

The discovery that cultured human endothelial cells can provide an in vitro model for Bartonella-host interactions has been a major technical advance for the field. These cell culture systems allow for the first-time study of pathogen-host interactions at a cellular and molecular level. ${ }^{17}$ Remarkably, it was shown by a number of investigators, including our group, that Bartonella induces proliferation of endothelial cells in vitro. ${ }^{18-20}$ Later, we determined that this proliferation results from potent antiapoptotic and promitotic effects. ${ }^{20}$ Furthermore, we established in vitro models of Bartonella-induced angiogenesis in which infected endothelial cells differentiate into primitive, canalized, capillary-like structures. ${ }^{21}$

Although much has been learned about pathogenhost interaction through use of these tissue culture models, the ability of these organisms to sustain chronic infection and produce its unique human pathologies can only be fully investigated using in vivo models. However, the major Bartonella species that infect humans do not cause sustained infection in either immunocompetent ${ }^{22}$ or immunodeficient mice. ${ }^{23}$ Nor have these species been observed to cause bacillary angiomatosis or peliosis lesions in rodents or other animals, ${ }^{1,22-24}$ with the exception of PCR identification of $B$. henselae from a dog with peliosis hepatis. ${ }^{25}$ Perhaps the rarity of these pathologies reflects an inability to achieve sufficient local organism concentrations in these hosts. With respect to this point, in vitro observations indicate that endothelial proliferative effects occur only when extremely high ratios of bacteria to endothelial cells are used. ${ }^{20,26}$ Presumably, immunocompromised hosts, who develop bacillary angiomatosis and peliosis, allow just such high local concentrations of organisms to accumulate through a compromised ability to clear organisms. ${ }^{27}$ Accumulating evidence in humans and animals indicates that Bartonella infection may also persist for prolonged periods in the immunocompetent host. ${ }^{28}$ Although disease pathologies are diverse (e.g., encephalopathy, endocarditis, arthritis, myocarditis) and potentially life threatening, ${ }^{29-31}$ these disease pathologies appear to be associated with much lower organisms burdens and likely result from unique pathogen-host interactions that are potentially distinct from those leading to pathologies associated with immunocompromised hosts.
We reasoned that the ability to adequately model human disease pathologies observed in immunocompromised hosts would require use of both a Bartonella strain that naturally infects mice and an immunodeficient host that permits development of a high local bacterial burden. Here we describe the ability of one species, Bartonella taylorii, to cause chronic high-level infection in the SCID/BEIGE immunocompromised mouse and produce pathologies with features similar to those observed in immunodeficient patients.

\section{Materials and Methods}

\section{Bacterial Strains and Culture}

B. birtlesii strains M39, P63, and Q73; B. doshiae strains C26, MAC35, R18, and 70WNH; B. grahamii strains F16, R16, and 33TDH; and B. taylorii strains LL-WM9, MAC36, and 8TBB were obtained from Richard Birtles (University of Liverpool, UK). Bacteria were grown on Columbia agar with 5\% sheep blood (BD Diagnostic Systems, Franklin Lakes, NJ); Columbia agar with $10 \%$ horse blood; or chocolate agar.

\section{Murine Strains and Infection}

A/J, SCID (Fox Chase SCID Outbred) and SCID/Beige (Fox Chase SCID/Beige), mice, 6 to 8 weeks of age, were purchased from Charles River Laboratory (Shrewsbury, MA). Mice were infected via intraperitoneal injection with 0.12 or $0.4 \mathrm{OD}_{600}$ units of bacteria suspended in RPMI 1640 medium. Control mice were mock infected with the same medium in the absence of bacteria. Bacteria were collected after a 1- to 2-day passage on solid media at which time they showed $>99 \%$ viability as assessed using the LIVE/DEAD BacLight Bacterial Viability Kit (Invitrogen, Carlsbad, CA). Based on realtime PCR quantification (qPCR; see below), $1 \mathrm{OD}_{600}$ unit was equivalent to approximately $8 \times 10^{9}$ genome copies of organism. At indicated times after infection, blood was collected in heparinized microtainers (BD Biosciences) and either plated to determine colonyforming units or frozen ( $B$. taylorii only) for later bacterial enumeration by GPCR. At the time of euthanasia, tissue was also fixed for microscopic analysis. Animal use was approved by our Institutional Animal Care and Use Committee.

\section{qPCR}

As colony-forming unit determinations appeared to underestimate bacterial burden (e.g., based on their tendency to form aggregates and not plate efficiently), a qPCR method was developed targeting the $B$. taylorii gltA gene for more accurate bacterial quantification during later studies. Primers were ascertained by aligning all available $B$. taylorii glt $A$ sequences using Vector NTI Advance 10.0.1 (Invitrogen, Carlsbad, CA) and choosing primer and probes from within completely conserved sequence. Among several primer sets tested, one gave robust and reliable amplification and 
was used for further experimental analysis, specifically primer glt1F, 5'-CATGACTTTGACCGTTGTATTATGC-3'; primer glt2R, 5'-CGTAACTAAGATCATTGCGTGGA-3'; and hydrolysis probe - FAM-TATGGCCGTTATGGTTGCATGCCTTGGA-IBFQ (FAM = 6-carboxyfluorescein; IBFQ = Black Hole Quencher 1). Primers were purchased from Invitrogen, and the probe was purchased from Integrated DNA Technology (Coralville, IA).

Bacterial nucleic acid was extracted from blood samples using the Promega Wizard Genomic DNA Purification Kit (Promega Corporation, Madison, WI) according to the manufacturer's instructions for isolating genomic DNA from Gram-negative bacteria with minor modifications. Briefly, after hypotonic lysis of red blood cells, bacteria were collected by centrifugation and then extracted with kit reagents. Before the final isoproponal precipitation step, $5 \mu \mathrm{g}$ glycogen (Invitrogen, Carlsbad, CA) was added to ensure quantitative precipitation of nucleic acid. Extracted nucleic acid (1.0 $\mu$ l) was added per $10 \mu \mathrm{l}$ PCR reaction containing DyNAmo Probe PCR master mix (New England BioLabs, Ipswich, MA), 50 $\mu \mathrm{mol} / \mathrm{L}$ of each primer, and $0.25 \mu \mathrm{mol} / \mathrm{L}$ of hydrolysis probe. Amplification was performed on an ABI $7900 \mathrm{HT}$ Fast Thermocycler (Applied Biosystems, Foster City, CA) with the following cycling parameters: 20 minutes at $95^{\circ} \mathrm{C}$ for hot start polymerase activation, followed by 40 cycles of $95^{\circ} \mathrm{C}$ for 10 seconds, $53^{\circ} \mathrm{C}$ for 15 seconds, and $68^{\circ} \mathrm{C}$ for 30 seconds.

To create a quantitative standard, the B. taylorii gltA PCR product was cloned into the TA cloning vector, pCR2.1Topo (Invitrogen, Carlsbad, CA). Purified gltATopo plasmid was quantified using a NanoDrop 1000 instrument (Thermo Fisher Scientific, Waltham, MA) and serially diluted to generate a calibration standard enabling conversion of real-time PCR cycle threshold values to gltA copies per unit of blood. Quantitative standards were mixed with blood and run through the same extraction procedure as samples to control for inefficiencies in the extraction procedure. In parallel experiments, run with and without supplementation with blood, we determined that the extraction method efficiently removed potential inhibitors in blood samples. The limit of detection of the assay was approximately 25 copies of gltA per reaction or 25,000 copies per $\mathrm{ml}$ of sample. Negative amplification controls were run with each set of qPCR assays and were consistently negative.

\section{Histopathology}

Mice were necropsied, tissue fixed in $4 \%$ paraformaldehyde, $1 \%$ glutaraldehyde, and processed for histopathology at several time points postinfection. SCID/Beige examined histopathologically were infected with $B$. taylorii for 14 days $(n=2), 59$ days $(n=2), 78$ days $(n=6), 91$ days $(n=2)$, and 114 days ( $n=6)$ and mock infected for 78 days $(n=3)$ and 114 days $(n=3)$, respectively. Hematoxylin and eosin, Brown and Brenn, Masson Trichrome, and Steiner stains were performed on 10- $\mu \mathrm{m}$ sections using standard methods. Digital images of slides were acquired using an Olympus BX-3 micro- scope, cropped, and otherwise only adjusted for contrast using Adobe Photoshop CS3 (San Jose, CA).

\section{Electron Microscopy}

Tissue specimens were fixed in Trump fixative containing $4 \%$ formaldehyde and $1 \%$ glutaraldehyde, washed in $0.1 \mathrm{M}$ cacodylate buffer, postfixed in $1 \% \mathrm{OsO}_{4}$, dehydrated in ascending alcohol washes, and embedded in Eponate. Ultrathin sections were stained with lead citrate, and digital images were acquired with a Jeol (Tokyo, Japan) MEM-1011 transmission electron microscope.

\section{Results}

To establish a murine model for Bartonella infection, we surveyed a wide variety of Bartonella species originally isolated from rodents. ${ }^{32,33}$ Previous observations suggested that Bartonella often loses virulence on serial media passage, ${ }^{12,34}$ potentially through loss of surface adhesins and other as yet unidentified factors. Consequently, in planning these experiments, there was concern that a significant fraction of Bartonella strains might already have lost their ability to infect mice. To increase the efficiency of identifying a virulent strain, we therefore performed initial experiments using equal mixtures of several strains for Bartonella grahamii, B. birtlesii, B. doshiae, and B. taylorii (see Materials and Methods section for designation of strains used in these mixtures). These mixtures were injected into $A / J$ (immunocompetent), SCID (B and T-cell deficient), and SCID/Beige (B-, T-, and NK-cell deficient) mice. In this pilot experiment we found that all four species groups caused short-term infection in immunocompetent A/J mice (20 to 8000 colony-forming units per $\mathrm{ml}$ ) as determined by positive blood cultures at approximately 2 weeks (Figure $1 A$ for $B$. taylorii, and data not shown for other species). However, at 2 months, organisms were no longer detectable by culture. In contrast, $B$. taylorii persisted at low levels at 2 months in SCID mice, and B. taylorii, B. grahamii, and B. birtlesii persisted for two months at high levels in SCID/Beige mice (Figure 1A for $B$. taylorii, and data not shown for other species). Interestingly, in B. taylorii and to a lesser extent B. birtlesii infections (data not shown), obvious and striking liver pathology developed by the three-month time point in the SCID/Beige mouse as described in detail for $B$. taylorii infections below.

Based on these findings, we sought to characterize $B$. taylorii infection in the SCID/Beige mouse as a potential model for chronic infection of the immunocompromised host. Of the three B. taylorii strains tested in the mixed infection, we found that only one caused pathologies (i.e., LL-WM9) when tested alone. Interestingly, this strain showed the slowest in vitro growth, taking up to three weeks to form colonies. This contrasted with the much faster growth of the other two strains. In addition, the other two strains formed morphologically distinct colonies that were smoother, less adherent to the agar, and easier to suspend in liquid medium. Therefore, we suspect that the latter two strains may have lost virulence on in vitro 
A

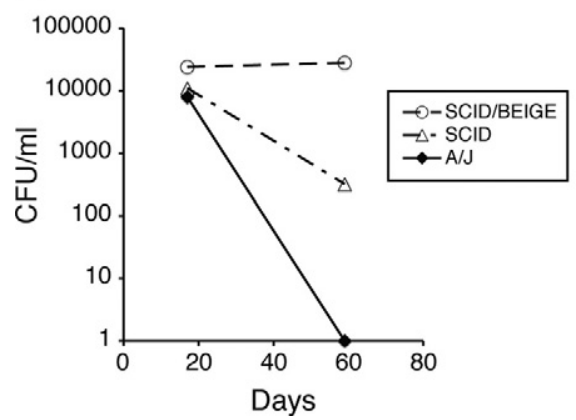

B

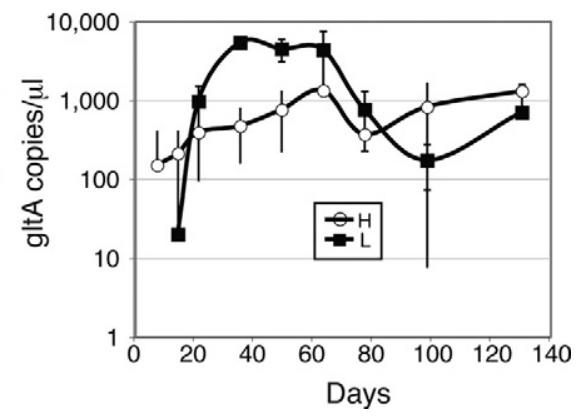

Figure 1. Bartonella taylorii causes sustained chronic blood stream infection in SCID/Beige mice. A: A/J, SCID, and SCID/Beige mice were inoculated by intraperitoneal injection with approximately $1.5 \times 10^{10}$ bacterial genome equivalents of B. taylorii. At indicated time points after infection, blood was collected and plated on bacterial media to determine colony forming units (CFU) as shown. B: SCID/Beige mice were infected with $B$. taylorii LL-WM9 at approximately $3 \times 10^{9}(\mathrm{H}, 4$ mice $)$ or $1 \times 10^{9}(\mathrm{~L}, 2$ mice $)$ genome copies. Blood was collected at indicated times postinfection and analyzed by qPCR to determine B. taylorii gltA gene copy number. As expected, the gltA sequence was not amplifiable from uninfected control animals ( 2 mice, data not shown). passage, a phenomenon previously associated in $B$. henselae with faster growth, smooth colony morphology, and loss or mutation of a major surface adhesin protein. ${ }^{35-37}$

Using B. taylorii strain LL-WM9, we then performed a series of experiments to characterize the bacteriological and histological progression of infection. We found that infections with this organism persisted for at least four months, at which time some of the infected animals (3 of 6 ), but none of the uninfected controls, became moribund or died. During this 4-month infectious course, animals were phlebotomized approximately every 2 weeks, and bacterial levels in the blood were quantified by qPCR. As shown in Figure 1B, the bacterial load increased during the first 1 to 2 months of infection reaching a plateau at greater than $1 \times 10^{6}$ organisms per ml. Mice infected with a larger inoculum developed detectable blood levels approximately one week earlier; however, a similarly high level of bacteremia was observed 1 month after infection irrespective of the initial dose.

\section{Histopathology}

During gross examination, no abnormalities were observed 2 months postinfection and earlier. However, at 4 months all mice had markedly enlarged spleens. By light microscopy, pathology was observed at earlier time points in multiple organs and evolved over time. At 1 month postinfection, a sparse myeloid infiltrate was noted in the liver (data not shown). This consisted primarily of neutrophil and band forms, occasionally occurring as nests of cells. These inflammatory cells likely represent either micro abscesses (neutrophils only) or foci of extramedullary hematopoiesis, which became more prominent at later time points. Also, at 1 and 2 months postin-
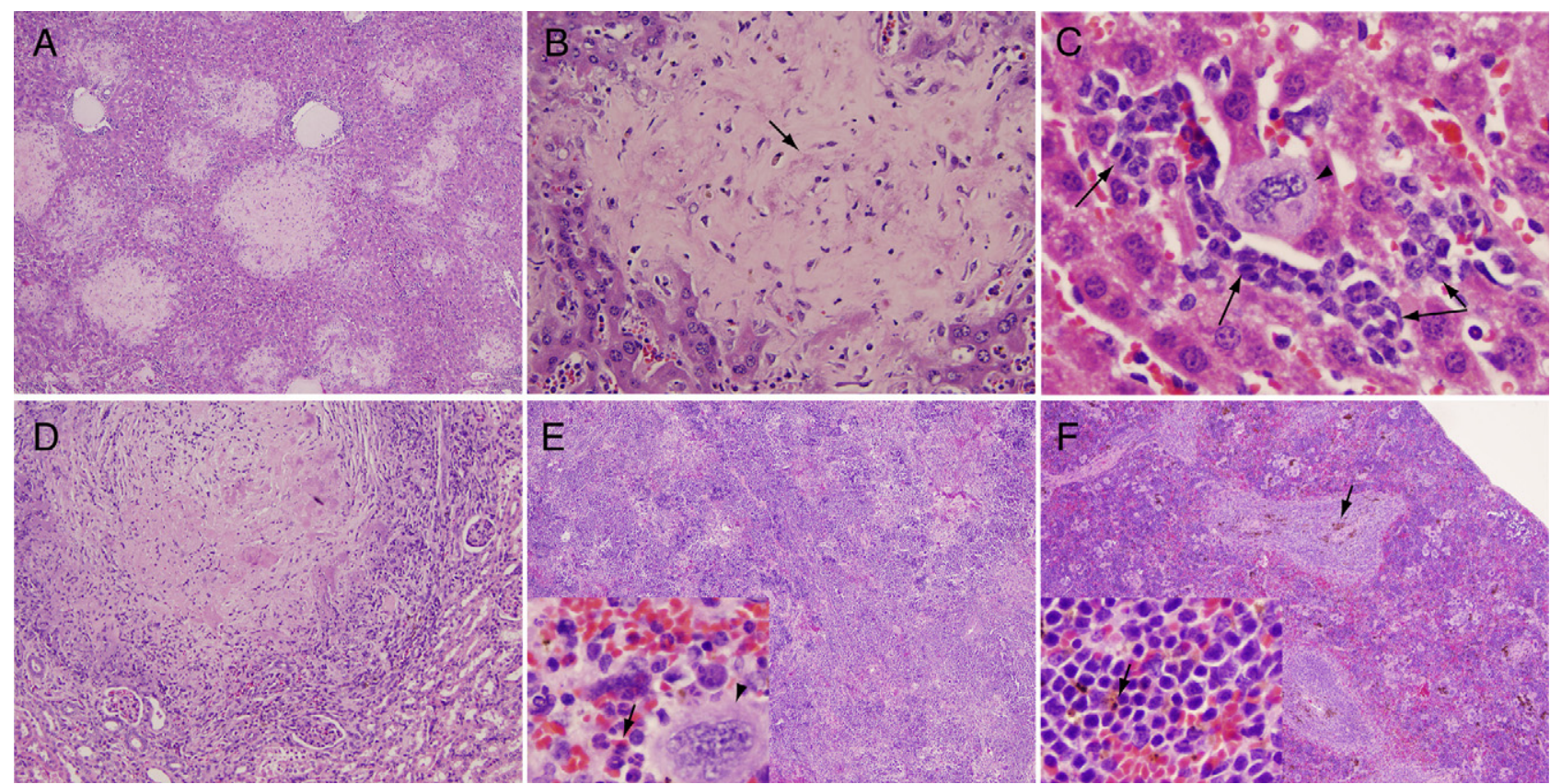

Figure 2. Liver, renal, and splenic pathology four months postinfection. A: Liver demonstrating multiple lesions, low power. B: Liver lesion, higher power. Note slightly purple filamentous material (e.g., arrow) that corresponds to bacteria in Steiner-stained sections. C: Liver nonlesional area showing extramedullary hematopoiesis. Megakaryocyte (arrowhead), myeloid cells (arrows). D: Kidney lesion, higher power. E: Spleen from infected animal with obliteration of normal architecture. Inset: high power showing myeloid cells (arrows) and a megakaryocyte (arrowhead). F: Spleen from uninfected control, arrows show hemosiderin pigment, less prominent but still visible in infected spleens. Original magnifications of $\mathbf{A}-\mathbf{F}$ and insets for $\mathbf{E}$ and $\mathbf{F}: \times 40, \times 200, \times 500, \times 200, \times 40$, $\times 40$, and $\times 500 \mathrm{X}$ and $\times 500 \mathrm{X}$, respectively. 
fection, a neutrophilic and mononuclear infiltrate was also observed focally in hepatic portal triads and around central veins indicative of a mild hepatitis. At three months, eosinophilic matrix-rich lesions were observed in the liver on hematoxylin and eosin-stained sections (Figure 2A). Embedded within the fibrillar eosinophilic matrix were spindle-shaped cells and foci of a slightly basophilic, filamentous haze (Figure 2B) corresponding to aggregates of bacteria in Steiner-stained sections (see below). The lesions appear to infiltrate into surrounding liver tissue without a distinct border, with occasional entrapment of liver cells and vascular structures. Smaller lesions often had a rim of neutrophil and mononuclear cells. Sinusoids adjacent to lesions were often dilated. At 4 months postinfection, lesions replaced up to half of the normal liver tissue (Figure 2, A and B) and were occasionally calcified. Rests of maturing myeloid cells and megakaryocytes were also present throughout the nonlesional area of liver tissue (Figure 2C). At four months, lesions of similar appearance were also noted in the kidney (Figure 2D) and suggested a form of granulomatous nephritis. All of the aforementioned findings were absent in uninfected controls.

At 2 months and earlier, spleens appeared similar in infected and uninfected mice-both contained distinct red and white pulp and a small number of hemosiderinladen macrophages (Figure 2F). Both infected and uninfected SCID/Beige mice showed a modest degree of extramedullary hematopoiesis that was greater in extent than in immunocompetent mice. However, by 3 months, spleens from infected animals (in contrast to uninfected animals) showed a loss of distinct red and white pulp architecture (Figure 2E) compared with uninfected controls (Figure 2F). Division into distinct zones of red and white pulp was no longer obvious. In addition, the spleens were infiltrated with leukemoid cells consisting predominantly of band forms and neutrophils (Figure 2E, inset). The general picture was one of extensive leftshifted extramedullary hematopoiesis.

These lesions were further characterized through use of multiple special stains. The Steiner stain, one of the silver stains traditionally used for identification of Bartonella in tissue sections, ${ }^{38}$ clearly demonstrated organisms in lesional areas. Organisms were present in small and large clusters, and individually (Figure 3A), reminiscent of their growth in cat scratch and bacillary angiomatosis lesions. Interestingly, organisms were also observed tracking along the abluminal surface of sinusoidal vessels adjoining and/or trapped within lesions (Figure 3B). At times, organisms encircled the entire cross section of blood vessels or sinusoids (arrowhead, Figure 3B) and occasionally appeared to invade into their lumens (e.g., arrow, Figure 3B). At these foci, it was not clear by light microscopy whether organisms were extracellular or within the endothelial cells surrounding these vascular channels. Notably, organisms were not observed in the nonlesional areas of the liver. In the kidney, organism clusters were also observed in lesional areas, and less conspicuously, surrounding and penetrating into peritubular renal vessels (Figure 3C, arrow) and infiltrating within interstitial tissue in the renal cortex (Figure 3C, arrowhead). In the spleen, organisms were found in large numbers in areas devoid of residual splenic cord architecture (Figure 3D).

In Masson trichrome-stained sections, the fibrillar matrix component of lesional areas in the liver (Figure 4A) and kidney stained blue, suggesting, based on properties of this stain, that the matrix consists largely of collagen fibers. At high power, these blue-staining fibers were noted to be organized in discrete parallel bundles (Figure 4B, arrowheads). These bundles often surrounded bacterial clusters circumferentially and merged with collagen surrounding centrilobular venules and triads. Interestingly, organisms were stained magenta by Masson
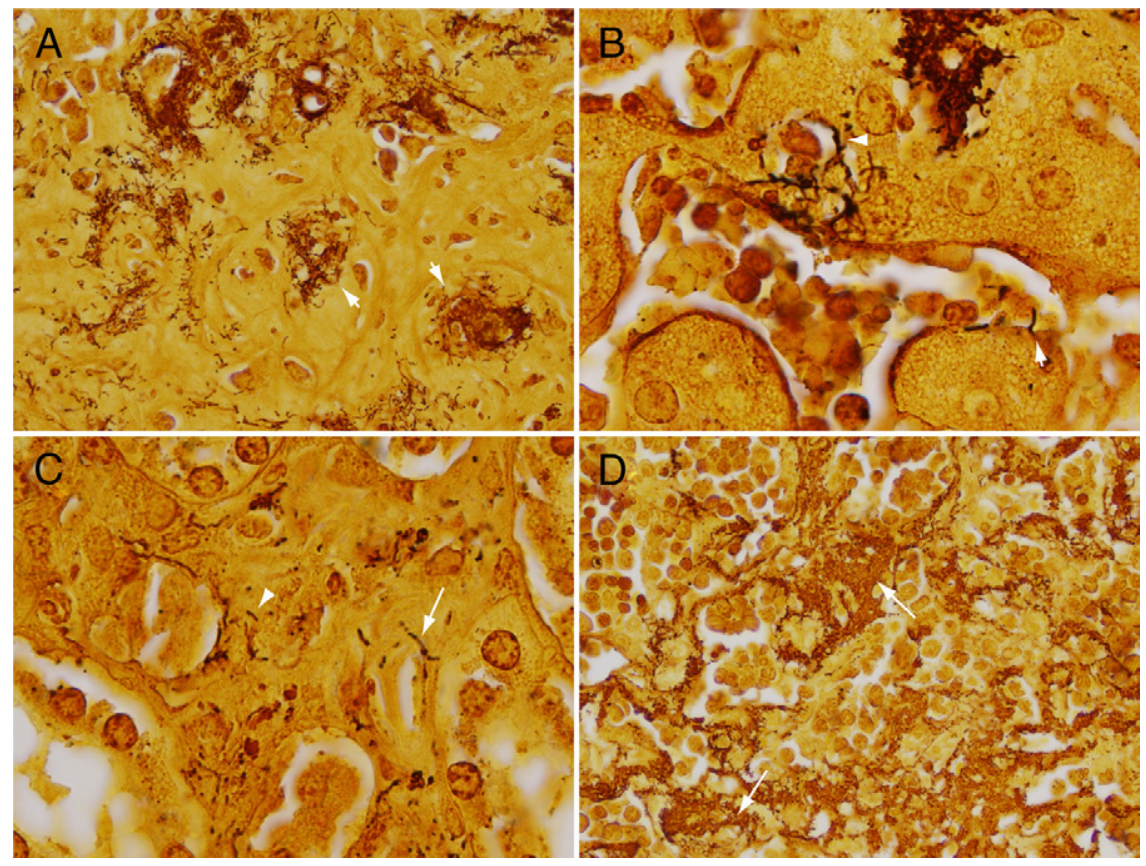

Figure 3. Steiner stain identifies organisms within affected tissues. A: Large clusters of organisms (arrows) are found within the matrix of liver lesions. B: Liver sinusoid adjoining lesional area. Note organisms surrounding a vessel (arrowhead) and invading into the lumen of the sinusoid (arrow). C: Kidney with organisms surrounding and invading into the wall of a peritubular arteriole (arrow) and in interstitial tissue (arrowhead). D: Spleen demonstrating abundance of infecting organisms growing as large aggregates (arrows). Original magnifications of A-D: $\times 500, \times 1000, \times 1000$, and $\times 500$, respectively. 

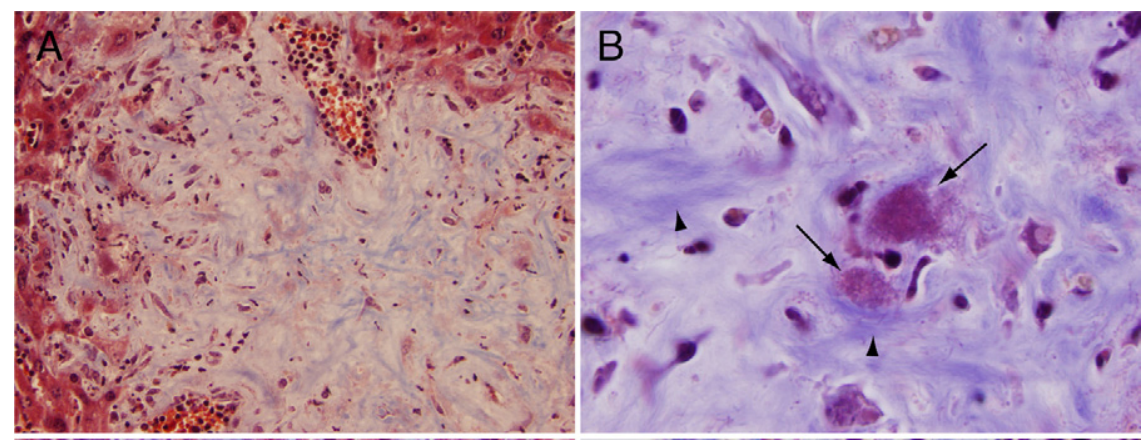

Figure 4. Trichrome stain demonstrates collagen-deposition response to bacteria. A: Liver showing blue-staining fibrillar collagen component of lesional area. B: Higher power of liver lesion showing relationship of collagen fibers (arrowheads) to acid fuchsin-staining bacteria (arrows). C: Kidney demonstrating collagen deposition in interstitial tissue in response to bacteria (not resolvable at this power). D: Spleen showing subcapsular collagen deposition in association with clusters (arrow) of acid-fuschin staining organisms. Original magnifications of $\mathbf{A}-\mathbf{D}: \times 200, \times 1000, \times 200$, and $\times 500$ respectively.

trichrome stain (Figure 4B, arrows), presumably related to the binding of the acid fuschin component of this stain. In contrast, staining with the Brown and Brenn tissue Gram stain was extremely faint to nonexistent (data not shown), suggesting, in contrast, that the basic fuschin component of the tissue Gram stain binds poorly. In the kidney, where organisms were observed in the interstitial tissue tracking along peritubular capillaries, they were also invariably surrounded by blue-staining fibrillar collagen deposits (Figure 4C). This deposition was especially prominent near larger blood vessels. At four months postinfection, a diffuse increase in blue-staining collagen matrix was also observed in the spleen, most prominent in areas containing substantial amounts of bacteria. Figure 4D, for example, shows subcapsular collagen deposits associated with large numbers of embedded bacteria. Taken together, the foregoing observations suggest a generalized collagen-deposition response to $B$. taylorii.

Pathology was not observed (data not shown) in histological sections of skin, heart, lungs, pancreas, intestine, and adrenal gland (when adequately sampled). Unfortunately, bone marrow was not saved for microscopic observation, although in retrospect there may have been significant marrow pathology based on extensive extramedullary hematopoiesis observed in the liver and spleen at later time points.

\section{Electron Microscopy}

Liver and spleen tissue were also examined by transmission electron microscopy (TEM) at 4 months postinfection to characterize the disease process at an ultrastructural level. By TEM, the noncellular component of the liver lesions (Figure 5A, arrows) was composed almost entirely of regularly sized fibrils (Figure 5B, arrow) arranged in parallel bundles. Fibers were $34 \pm 4$ nanometers in diameter (based on average and SD of five measurements) and showed a D banding pattern (Figure 5B, bracket), alternating dark and lighter staining bands with an approximately $53 \pm 3$ nanometer periodicity, consistent with previous descriptions of glutaraldehyde-fixed collagen fibers. ${ }^{39,40}$ The cells lying within this collagen matrix included stellate-shaped cells, entrapped capillary vessels, and myeloid cells. The stellate-shaped cells were irregularly shaped, occasionally extended long cellular processes, and contained abundant, often grossly swollen rough endoplasmic reticulum (Figure 5C, arrow). Some of these cells appeared to be actively depositing collagen fibrils, as indicated by the short collagen fibers emanating perpendicularly from their surface (Figure 5D, arrow).

By TEM, the spleen showed areas rich in macrophages, myeloid cells (Figure 6A, arrowheads), and red cells (Figure 6A, asterisk). These cells were often arranged in a linear fashion suggestive of residual splenic cord architecture. Interspersed among these cellular areas were zones containing large numbers of bacteria (Figure 6A, short arrows). Bacteria were generally surrounded by collagen fibers (Figure 6B, short arrows). However, in contrast to liver lesions (Figure 5D, arrow), collagen fibrils were organized haphazardly as indicated by interspersed fibers cut on face and in cross section (Figure 6B, arrows). Also, there were clear spaces within and between foci of bacteria and collagen matrix (Figure 6 , A and B, long arrows), suggesting the presence of edema.

By TEM, the trilaminar cell membrane structure characteristic of Bartonella and other Gram-negative organisms was clearly demonstrated (Figure 5E, arrow). In addition, the bacteria showed a rough feathered outer surface layer extending from their membrane (Figure 5E, arrowhead). This surface layer appeared similar in 

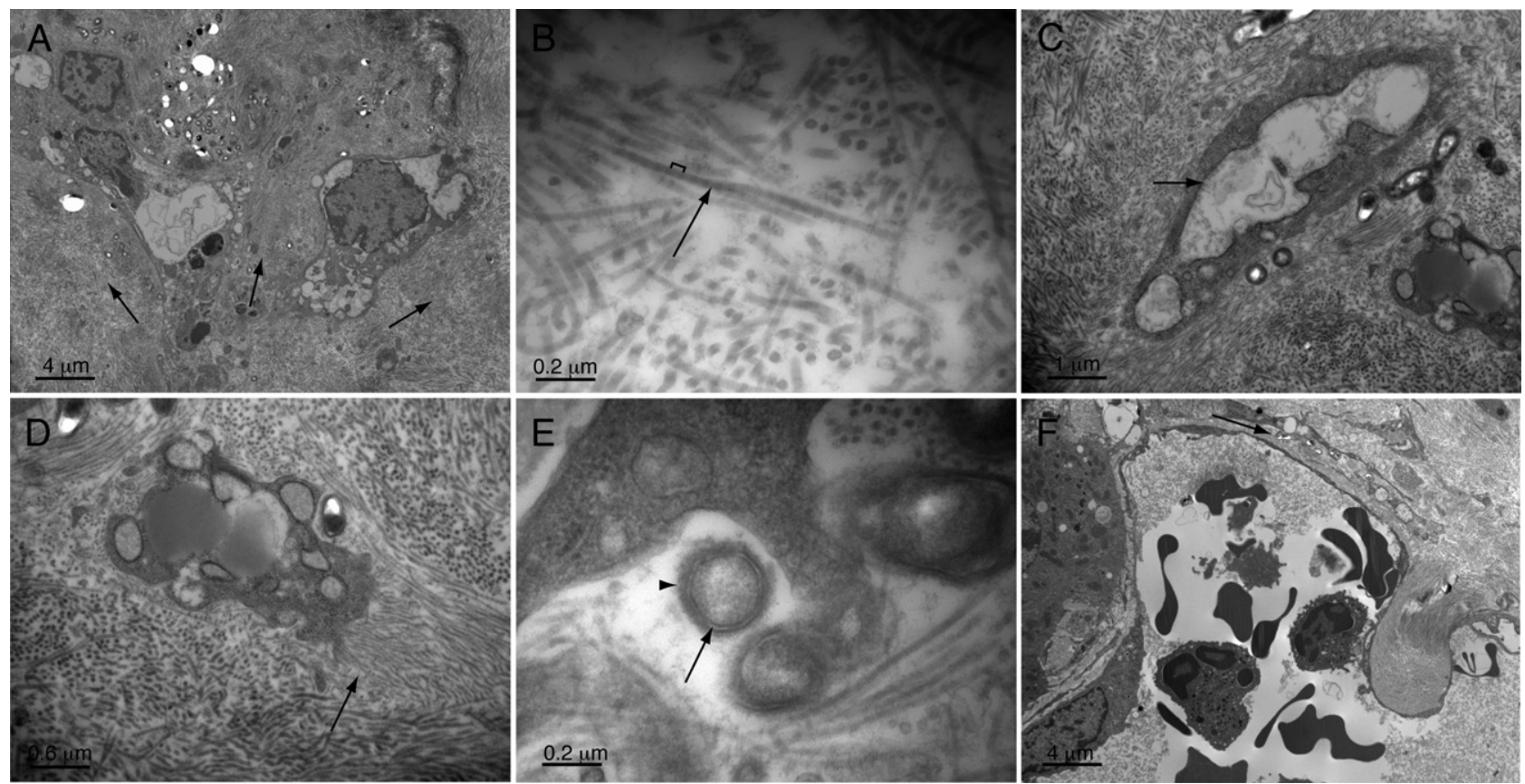

Figure 5. Ultrastructural pathology of the liver. A: Lesional area (with fibrillar matrix indicated by arrows). B: Fibers within lesions (arrow) show banding pattern (bracket) consistent with collagen. C: Stellate-shaped eukaryotic cells within lesion matrix show grossly dilated, rough endoplasmic reticulum (arrow) indicative of a high degree of synthetic activity. D: Higher power image of eukaryotic cell that appears to be laying down new collagen fibers (arrow) perpendicular to its surface. E: Bacteria within tissue show trilaminar staining pattern (arrow) characteristic of Gram-negative bacteria and a rough outer surface (arrowhead) F: Liver sinusoid with bacteria (arrow) tracking just outside of a sinusoidal space. Magnifications in $\mathbf{A}-\mathbf{F}: \times 1,700, \times 26,900, \times 6,400, \times 10,100, \times 33,700$, and $\times 1,700$, respectively.

breadth to the BadA adhesin coat previously observed in $B$. henselae organisms ex vivo ${ }^{36,37}$ and the rough ultrastructural surface appearance of $B$. henselae observable in electron micrographs of human infection. ${ }^{41}$ Notably, in many of the larger clusters of organism in liver and spleen, organisms appeared embedded in an amorphous matrix-like material with granular and modestly osmophilic staining properties (Figure 6, C and D, ar- rows). However, additional ultrastructural properties of this material were not further resolvable by TEM at $\times 120,000$ magnification (data not shown).

Interestingly, despite the large numbers of organisms examined by TEM, they were never observed within endothelial cells or other cell types with the exception of a few bacteria appearing within collagen-matrix embedded cells. In these cases, it was often not clear whether bacteria
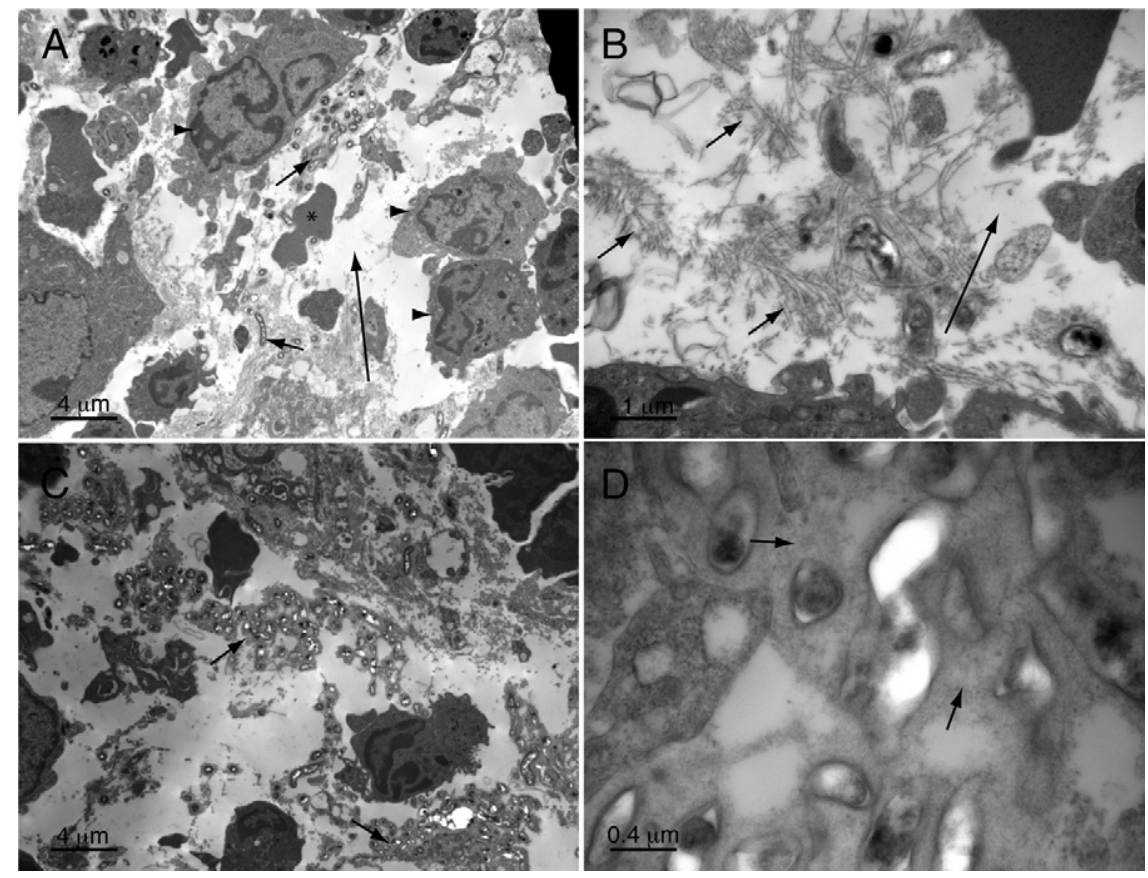

Figure 6. Ultrastructural pathology of the spleen. A: Lower power image demonstrating myeloid infiltrate (arrowheads), bacteria (short arrows), red cells (asterisk), and edema (electron-lucent areas, long arrow). B: Higher power images showing bacteria surrounded by a relatively haphazard arrangement of collagen fibers (arrows) in comparison with liver lesions and edema (long arrow). C: Bacterial aggregates embedded in an osmophilic granular matrix (arrows). D: Higher power image of matrix (arrows) and embedded bacteria. Magnifications in $\mathbf{A}-\mathbf{D}: \times 1700, \times 6,500, \times 1,700$, and $\times 17,100$, respectively. 
were within vacuoles or within extracellular surface invaginations. When observed in juxtaposition to sinusoids, organisms (Figure 5F, arrow) were found extracellularly in the space of Disse rather than in endothelial cells themselves. Therefore, by TEM, the organisms did not appear to make extensive use of an intracellular niche.

\section{Discussion}

Using the rodent pathogen, Bartonella taylorii, and the SCID/Beige mouse, we have established a new model for chronic Bartonella infection. Based on pathological findings, we believe it provides an excellent experimental model for human disease in the immunocompromised host. We discuss our findings below in the context of pathological observations during human infection.

Immunocompromised humans sustain chronic Bartonella infection of the bloodstream, placing them at particular risk for endovascular infection. Notably, in our study, mice similarly develop chronic blood stream infection, sustained at a very high level for at least 4 months. A very high-level, seemingly well-tolerated chronic bacteremia was also previously described in Rag1 knockout mice infected with Bartonella grahamii. ${ }^{24}$ Therefore, just like humans, immunocompromised mice tolerate chronic, high-level $B$. taylorii infection to a remarkable degree. This tolerance contrasts markedly with what would be expected during bacteremia with other Gram-negative pathogens, where shock and death would usually follow quickly without prompt antimicrobial therapy. Presumably, the ability of the Bartonella genus to sustain blood stream infection without immobilizing their hosts promotes efficient acquisition by blood-sucking arthropod vectors. The relatively asymptomatic host can roam about, leading to contact with vectors, and high levels of organism in the blood ensure efficient acquisition by the vector during a blood meal. Therefore, this property of relatively benign coexistence with the host, reproduced in this model, is likely a critical part of Bartonella's life cycle.

The geometry of growth within murine tissues also demonstrated similarity with human disease. As in human cat scratch disease, bacillary angiomatosis, and bacillary peliosis, organisms grew in large aggregates, rather than in a more dispersed fashion typical of other bacterial infections. What is responsible for this unusual aggregative growth, and how might this contribute to pathogenesis? It has been noted previously that Bartonella express surface adhesins and stick avidly to one another. ${ }^{34}$ This is also observed during in vitro experiments. For example, in tissue culture media organisms grow as large floating balls, sometimes large enough to visualize by the naked eye, and also stick to and grow as microcolonies on the surface of tissue culture plastic (Kirby, unpublished observation). Furthermore, colonies formed on agar medium are also difficult to disperse, again suggesting strong interbacterial adherence.

Our TEM observations of mouse tissue and bacterial colonies (data not shown) suggest an additional potential contribution to aggregative growth. Bacteria appear to elaborate and embed themselves in a matrix (Figure 6, C and D). Although the nature of this material is not known, the general characteristics suggest growth in a biofilm, although it is possible this represents solely excessive elaboration of bacterial adhesin material. Growth in biofilm is believed responsible for persistence of human pathogens infecting prosthetic materials, and in some types of infections involving growth on tissue surfaces (e.g., endocarditis). ${ }^{42}$ Based on our findings, we hypothesize that aggregative growth and/or biofilm also play a very important role in the Bartonella life cycle. Through these processes, organisms presumably avoid phagocytosis and penetration of antibacterial activities (either host derived or antibiotics). Of note, aggregative growth is consistently observed in both cat scratch disease and bacillary angiomatosis. However, biofilm formation has not yet been systemically investigated, and it is possible that this phenotype may prove more prominent with this particular host-pathogen combination.

The high concentrations of organisms in tissues is another feature shared with human disease. As mentioned in the introduction, Bartonella appear to produce trophic factors, which act in a paracrine fashion to stimulate angiogenesis. During in vitro experiments, large numbers of organisms are required to induce significant endothelial proliferation. Based on qPCR results presented here, we now believe that previously estimated bacterial densities required for optimal proliferative effects were an underestimate, and the requirement may be upwards of 4000 genome copies of organisms per eukaryotic cell. Interestingly, such large local concentrations of bacteria are observed in human peliosis hepatis and bacillary angiomatosis, where organisms are found embedded as large clusters within extracellular matrix surrounding endothelial cells. Taken together, these observations suggest that the establishment of high local organism density in an in vivo model might be required to observe the full range of Bartonella pathologies. Importantly, use of an immunocompromised murine host in our experiments allowed such accumulation to occur-an accumulation associated with a profound, localized host response (i.e., collagen-deposition response around bacteria and granulomatous nodule formation).

How then do histopathological observations in the murine model compare with human disease? We first comment on the matrix response. One of the most remarkable features of murine infection is the profound collagen deposition response in the liver, spleen, and kidney. Histopathological descriptions of human disease generally focus on the proliferating cellular component of the host response. However, a profound matrix response-not yet fully characterized, but consisting of collagen fiber deposition at least in part-is a noted feature. In bacillary angiomatosis, proliferating capillary structures are embedded in an as yet ill-defined extracellular matrix composed of bacteria, immune cells, and a fibromyxoid ground substance. ${ }^{43,44}$ In terms of description of the matrix component of bacillary angiomatosis lesions, one study described the presence of fibrous long-spacing collagen closely associated with organisms in bacillary angiomatosis lesions, ${ }^{45}$ whereas an additional TEM study 
indicated that organisms were found extracellularly "amid collagen fibrils." ${ }^{" 46} \mathrm{~A}$ study by the same group indicated that the early stroma of BA is edematous, becoming fibrotic (i.e., collagen deposition) in later lesions. ${ }^{27}$ In the related angioproliferative disease caused by $B$. bacilliformis (i.e., verruga peruana), an angioproliferative response was noted to progress through stages, starting out predominantly as a proliferation of endothelial cells, progressing through a fibrotic stage, and then through resorption and resolution of lesions. Organisms were noted to be surrounded by abundant amorphous material, especially when found within endothelial phagosomes, a rare occurrence, associated with degradation of organisms. ${ }^{47}$ In these cases, surrounding matrix composed of collagen fibrils was also noted to be engulfed. ${ }^{47}$ In a separate TEM-based study, organisms were noted to be associated with fibrils of an unspecified type (but perhaps representing a collagen response) in interstitial spaces. ${ }^{15}$

In bacillary peliosis, organisms were noted to lie within a variably edematous matrix adjoining dilated vascular spaces in both liver and spleen. ${ }^{43}$ In one study, organisms were described as embedded within the fibromyxoid stroma surrounding these vascular spaces/sinusoidal spaces. A TEM micrograph shows organisms embedded among what appear to be fibers morphologically consistent with collagen, although these are not specifically identified in the study. ${ }^{16}$

In the murine model, the collagen deposition response appeared to be especially prominent. The liver lesions resembled an atypical form of granulomatous inflammation-fibrotic core surrounded by a thick rim of white blood cells in earlier lesions. Interestingly, in some AIDS patients, very similar liver lesions were observed, described as "necro-inflammatory nodules," ${ }^{41}$ some associated with peripheral dilation of sinusoids, perhaps representing an intermediate stage between nodular and peliotic lesions. It should be noted, however, that organisms in the murine model were also surrounded by collagen in the interstitium of the kidney and spleen in areas that lacked the nodular and potentially granulomatous circumscription found in the liver and in some kidney lesions. We therefore postulate that collagen deposition is a general pathological response to this organism, whether in tissues of our murine mode, or the fibromyxoid stroma of bacillary angiomatosis and peliotic lesions in humans. Presumably, this response allows the host to physically contain the organisms. However, in doing so, it may also further physically protect the organisms from clearance by the host immune response. Interestingly, in previous in vitro experiments, Bartonella has been shown to avidly bind collagen through surface adhesion proteins, ${ }^{48-50}$ and therefore the organism may actively participate in this potentially beneficial association with collagen fibers observed in vivo. The generalized collagen response might more generally be considered an abnormal or incomplete granulomatous response that as a result of the nature of the organs affected or timing of histological observation, might not manifest in identifiable granulomatous circumscription. In this respect, it is interesting to speculate whether bacillary angiomatosis and peliosis might be manifestations of an atypical granulomatous response in the immunocompromised patientwith an especially prominent vascular component-arising from the unique interactions of pathogen and host blood vessels.

An additional similarity with human disease should be noted. Organisms were not observed intracellularly to any significant extent, despite the large numbers of organisms present, which should have made such events more easily visible. This is consistent with prior observations in human disease. ${ }^{47,51,52}$ However, this observation contrasts with predictions from tissue culture models. First, Bartonella was previously shown to invade into human umbilical vein endothelial cells. ${ }^{53}$ Second, several studies provided evidence for intracellular replication within cultured endothelial cells. ${ }^{19,54}$ Last, evidence for survival and replication of $B$. henselae in erythroid ${ }^{55}$ and endothelial ${ }^{56}$ progenitor cells was also recently described. There may be several reasons for the lack of observation of endothelial invasion and intracellular replication in vivo. For example, Bartonella may only replicate in specific vascular beds not examined in our study. Alternatively, tissue culture models may not adequately reproduce the biology of mammalian infection. In any case, Bartonella appears in vivo to survive and replicate to a large extent in an extracellular milieu in both humans and the mouse model.

Despite these several similarities, a pure endothelial proliferative response similar to bacillary angiomatosis was not observed in the murine model. Therefore, the murine host is either less susceptible to bacterial-induced endothelial proliferative effects, and/or this Bartonella species lacks factors capable of inducing endothelial proliferation. Nevertheless, this new model lays the basis for investigation of the pathogen-host relationships that foster chronic infection. Furthermore, with the establishment of a chronic murine infection model, it should be possible to introduce genes from bacillary angiomatosisassociated species and test whether they are sufficient to induce endothelial proliferation in vivo, potentially further extending our ability to model human disease.

Based on the findings in this model, a general model for pathogen-host interaction is proposed in which bacteria replicate extracellularly, predominantly within the liver and spleen. There they establish a stabile, protected, predominantly extracellular niche within matrix elaborated by both host (collagen) and bacteria (adhesin, biofilm). The presence of aggregates of organisms situated in proximity to the draining circulation of liver and spleen (sinusoids and cords, respectively) allows organisms to be shed at consistently high levels into the blood stream. Hemotropic infection (red blood cell infection) described elsewhere ${ }^{57}$ likely also contributes to maintenance of infection, especially in hosts with more intact immunity. Blood-sucking arthropod vectors transmit organisms to the next host, completing the life cycle. The murine model described here should provide an experimental basis for further refining this model and hasten our understanding of Bartonella-host interaction in the immunodeficient host. 


\section{Acknowledgment}

We thank German Pihan for use of his light microscope for image acquisition and valued discussions about histopathological findings.

\section{References}

1. Breitschwerdt EB, Kordick DL: Bartonella infection in animals: carriership, reservoir potential, pathogenicity, and zoonotic potential for human infection. Clin Microbiol Rev 2000, 13:428-438

2. Maggi RG, Raverty SA, Lester SJ, Huff DG, Haulena M, Ford SL, Nielsen O, Robinson $\mathrm{JH}$, Breitschwerdt EB: Bartonella henselae in captive and hunter-harvested beluga (Delphinapterus leucas). J Wildl Dis 2008, 44:871-877

3. Fournier PE, Taylor C, Rolain JM, Barrassi L, Smith G, Raoult D: Bartonella australis sp. nov. from kangaroos, Australia. Emerg Infect Dis 2007, 13:1961-1962

4. Concannon R, Wynn-Owen K, Simpson VR, Birtles RJ: Molecular characterization of haemoparasites infecting bats (Microchiroptera) in Cornwall, UK. Parasitology 2005, 131:489-496

5. Telfer S, Begon M, Bennett M, Bown KJ, Burthe S, Lambin X, Telford G, Birtles R: Contrasting dynamics of Bartonella spp. in cyclic field vole populations: the impact of vector and host dynamics. Parasitology 2007, 134:413-425

6. Dehio C, Lanz C, Pohl R, Behrens P, Bermond D, Piemont Y, Pelz K, Sander A: Bartonella schoenbuchii sp. nov., isolated from the blood of wild roe deer. Int J Syst Evol Microbiol 2001, 51:1557-1565

7. Valentine $\mathrm{KH}$, Harms CA, Cadenas MB, Birkenheuer AJ, Marr HS, Braun-McNeill J, Maggi RG, Breitschwerdt EB: Bartonella DNA in loggerhead sea turtles. Emerg Infect Dis 2007, 13:949-950

8. Bai Y, Kosoy MY, Ray C, Brinkerhoff RJ, Collinge SK: Temporal and spatial patterns of Bartonella infection in black-tailed prairie dogs (Cynomys ludovicianus). Microb Ecol 2008, 56:373-382

9. Mediannikov O, Ivanov L, Zdanovskaya N, Vysochina N, Fournier PE, Tarasevich I, Raoult D: Molecular screening of Bartonella species in rodents from the Russian Far East. Ann NY Acad Sci 2005, 1063:308-311

10. Matsumoto K, Berrada ZL, Klinger E, Goethert HK, Telford SR 3rd: Molecular detection of Bartonella schoenbuchensis from ectoparasites of deer in Massachusetts, Vector Borne Zoonotic Dis 2008, 8:549-554

11. Cherry NA, Maggi RG, Cannedy AL, Breitschwerdt EB: PCR detection of Bartonella bovis and Bartonella henselae in the blood of beef cattle. Vet Microbiol 2009, 135:308-312

12. Anderson BE, Neuman MA: Bartonella spp. as emerging human pathogens. Clin Microbiol Rev 1997, 10:203-219

13. Sander A, Posselt M, Oberle K, Bredt W: Seroprevalence of antibodies to Bartonella henselae in patients with cat scratch disease and in healthy controls: evaluation and comparison of two commercial serological tests. Clin Diagn Lab Immunol 1998, 5:486-490

14. Iralu J, Bai Y, Crook L, Tempest B, Simpson G, Mckenzie T, Koster F: Rodent-associated Bartonella febrile illness, Southwestern United States. Emerg Infect Dis 2006, 12:1081-1086

15. Recavarren S, Lumbreras H: Pathogenesis of the verruga of Carrion's disease. Ultrastructural studies. Am J Pathol 1972, 66:461-470

16. Perkocha LA, Geaghan SM, Yen TS, Nishimura SL, Chan SP, GarciaKennedy R, Honda G, Stoloff AC, Klein HZ, Goldman RL: Clinical and pathological features of bacillary peliosis hepatis in association with human immunodeficiency virus infection. N Engl J Med 1990, 323:1581-1586

17. Conley T, Slater L, Hamilton K: Rochalimaea species stimulate human endothelial cell proliferation and migration in vitro. $\mathrm{J}$ Lab Clin Med 1994, 124:521-528

18. Dehio C: Recent progress in understanding Bartonella-induced vascular proliferation. Curr Opin Microbiol 2003, 6:61-65

19. Kempf VA, Volkmann B, Schaller M, Sander CA, Alitalo K, Riess T, Autenrieth IB: Evidence of a leading role for VEGF in Bartonella henselae-induced endothelial cell proliferations. Cell Microbiol 2001, 3:623-632

20. Kirby JE, Nekorchuk DM: Bartonella-associated endothelial prolifer- ation depends on inhibition of apoptosis. Proc Natl Acad Sci U S A 2002, 99:4656-4661

21. Kirby JE: In vitro model of Bartonella henselae-induced angiogenesis. Infect Immun 2004, 72:7315-7317

22. Regnath T, Mielke ME, Arvand M, Hahn H: Murine model of Bartonella henselae infection in the immunocompetent host. Infect Immun 1998 , 66:5534-5536

23. Velho PS, Moraes AM, Cintra ML, Giglioli R, Goncalves SA, Shlessarenko N, Camargo ME: Baccilary angiomatosis: negative results using normal Balb/c and Balb/c nude mice. Braz J Infect Dis 1998, 2:300-303

24. Koesling J, Aebischer T, Falch C, Schulein R, Dehio C: Cutting edge: antibody-mediated cessation of hemotropic infection by the intraerythrocytic mouse pathogen Bartonella grahamii. J Immunol 2001, 167:11-14

25. Kitchell BE, Fan TM, Kordick D, Breitschwerdt EB, Wollenberg G, Lichtensteiger CA: Peliosis hepatis in a dog infected with Bartonella henselae. J Am Vet Med Assoc 2000, 216:519-523

26. Maeno N, Oda H, Yoshiie K, Wahid MR, Fujimura T, Matayoshi S: Live Bartonella henselae enhances endothelial cell proliferation without direct contact. Microb Pathog 1999, 27:419-427

27. Cockerell CJ, LeBoit PE: Bacillary angiomatosis: a newly characterized, pseudoneoplastic, infectious, cutaneous vascular disorder. J Am Acad Dermatol 1990, 22:501-512

28. Chomel BB, Kasten RW, Sykes JE, Boulouis HJ, Breitschwerdt EB: Clinical impact of persistent Bartonella bacteremia in humans and animals 2003, 990:267-278

29. Meininger GR, Nadasdy T, Hruban $\mathrm{RH}$, Bollinger RC, Baughman KL, Hare JM: Chronic active myocarditis following acute Bartonella henselae infection (cat scratch disease). Am J Surg Pathol 2001, 25:1211-1214

30. Breitschwerdt EB, Maggi RG: Comparative medical features of canine and human bartonellosis. Clinical Microbiology and Infection 2009, 15:106-107

31. Maman E, Bickels J, Ephros M, Paran D, Comaneshter D, MetzkorCotter E, Avidor B, Varon-Graidy M, Wientroub S, Giladi M: Musculoskeletal manifestations of cat scratch disease. Clin Infect Dis 2007, 45:1535-1540

32. Birtles RJ, Hazel SM, Bennett M, Bown K, Raoult D, Begon M: Longitudinal monitoring of the dynamics of infections due to Bartonella species in UK woodland rodents. Epidemiol Infect 2001, 126:323-329

33. Birtles RJ, Harrison TG, Saunders NA, Molyneux DH: Proposals to unify the genera Grahamella and Bartonella, with descriptions of Bartonella talpae comb. nov. Bartonella peromysci comb nov, and three new species, Bartonella grahamii sp nov, Bartonella taylorii sp nov, and Bartonella doshiae sp nov. Int J Syst Bacteriol 1995, 45:1-8

34. Kyme P, Dillon B, Iredell J: Phase variation in Bartonella henselae. Microbiology 2003, 149:621-629

35. Gilmore RD Jr, Bellville TM, Sviat SL, Frace M: The Bartonella vinsonii subsp. arupensis immunodominant surface antigen BrpA gene. Encoding a 382-kilodalton protein composed of repetitive sequences, is a member of a multigene family conserved among bartonella species. Infect Immun 2005, 73:3128-3136

36. Riess T, Andersson S, Lupas A, Schaller M, Schafer A, Kyme P, Martin J, Walzlein JH, Ehehalt $U$, Lindroos $H$, Schirle M, Nordheim A, Autenrieth IB, Kempf VA: Bartonella adhesin A mediates a proangiogenic host cell response. J Exp Med 2004, 200:1267-1278

37. Batterman HJ, Peek JA, Loutit JS, Falkow S, Tompkins LS: Bartonella henselae and Bartonella quintana adherence to and entry in cultured human epithelial cells. Infect Immun 1995, 63:4553-4556

38. Warren K, Goldstein E, Hung VS, Koehler JE, Richardson W: Use of retinal biopsy to diagnose Bartonella (formerly Rochalimaea) henselae retinitis in an HIV-infected patient. Arch Ophthalmol 1998, 116:937-940

39. Bender E, Silver FH, Hayashi K, Trelstad RL: Type I collagen segment long spacing banding patterns. Evidence that the alpha 2 chain is in the reference or A position. J Biol Chem 1982, 257:9653-9657

40. Ortolani F, Marchini M: Cartilage type II collagen fibrils show distinctive negative-staining band patterns differences between type II and type I unfixed or glutaraldehyde-fixed collagen fibrils. J Electron Microsc (Tokyo) 1995, 44:365-375

41. Slater LN, Pitha JV, Herrera L, Hughson MD, Min KW, Reed JA: Rochalimaea henselae infection in acquired immunodeficiency syndrome causing inflammatory disease without angiomatosis or pelio- 
sis. Demonstration by immunocytochemistry and corroboration by DNA amplification. Arch Pathol Lab Med 1994, 118:33-38

42. Lynch AS, Robertson GT: Bacterial and fungal biofilm infections. Annu Rev Med 2008, 59:415-428

43. Slater LN, Welch DF, Min KW: Rochalimaea henselae causes bacillary angiomatosis and peliosis hepatis. Arch Intern Med 1992, 152:602-606

44. Karem KL, Paddock CD, Regnery RL: Bartonella henselae. B quintana, and $\mathrm{B}$ bacilliformis: historical pathogens of emerging significance. Microbes Infect 2000, 2:1193-1205

45. Borczuk AC, Niedt G, Sablay LB, Kress Y, Mannion CM, Factor SM, Tanaka KE: Fibrous long-spacing collagen in bacillary angiomatosis. Ultrastruct Pathol 1998, 22:127-133

46. Cockerell CJ, Tierno PM, Friedman-Kien AE, Kim KS: Clinical, histologic, microbiologic, and biochemical characterization of the causative agent of bacillary (epithelioid) angiomatosis: a rickettsial illness with features of bartonellosis. J Invest Dermatol 1991, 97:812-817

47. Arias-Stella J, Lieberman PH, Erlandson RA, Arias-Stella JJ: Histology, immunohistochemistry, and ultrastructure of the verruga in Carrion's Disease. Am J Surg Pathol 1986, 10:595-610

48. Dabo SM, Confer AW, Saliki JT, Anderson BE: Binding of Bartonella henselae to extracellular molecules: identification of potential adhesins. Microbial Pathogenesis 2006, 41:10-20

49. Kaiser PO, Riess $T$, Wagner CL, Linke D, Lupas AN, Schwarz $H$, Raddatz G, Schafer A, Kempf VA: The head of Bartonella adhesin A is crucial for host cell interaction of Bartonella henselae. Cell Microbiol 2008, 10:2223-2234

50. Zhang P, Chomel BB, Schau MK, Goo JS, Droz S, Kelminson KL, George SS, Lerche NW, Koehler JE: A family of variably expressed outer-membrane proteins (Vomp) mediates adhesion and autoaggregation in Bartonella quintana. Proc Natl Acad Sci U SA 2004, 101:13630-13635
51. LeBoit PE, Berger TG, Egbert BM, Beckstead JH, Yen TS, Stoler $\mathrm{MH}$ : Bacillary angiomatosis. The histopathology and differential diagnosis of a pseudoneoplastic infection in patients with human immunodeficiency virus disease. Am J Surg Pathol 1989, 13: 909-920

52. Bhutto AM, Nonaka S, Hashiguchi Y, Gomez EA: Histopathological and electron microscopical features of skin lesions in a patient with bartonellosis (verruga peruana). J Dermatol 1994, 21:178-184

53. Dehio C, Meyer M, Berger J, Schwarz H, Lanz C: Interaction of Bartonella henselae with endothelial cells results in bacterial aggregation on the cell surface and the subsequent engulfment and internalisation of the bacterial aggregate by a unique structure, the invasome. J Cell Sci 1997, 110:2141-2154

54. Kempf VA, Schaller M, Behrendt S, Volkmann B, Aepfelbacher M, Cakman I, Autenrieth IB: Interaction of Bartonella henselae with endothelial cells results in rapid bacterial rRNA synthesis and replication. Cell Microbiol 2000, 2:431-441

55. Mandle T, Einsele H, Schaller M, Neumann D, Vogel W, Autenrieth IB, Kempf VA: Infection of human CD34+ progenitor cells with Bartonella henselae results in intraerythrocytic presence of B. henselae. Blood 2005, 106:1215-1222

56. Salvatore P, Casamassimi A, Sommese L, Fiorito C, Ciccodicola A Rossiello R, Avallone B, Grimaldi V, Costa V, Rienzo M, Colicchio R, Williams-Ignarro S, Pagliarulo C, Prudente ME, Abbondanza C, Lamberti F, Baroni A, Buommino E, Farzati B, Tufano MA, Ignarro LJ, Napoli C: Detrimental effects of Bartonella henselae are counteracted by L-arginine and nitric oxide in human endothelial progenitor cells, Proc Natl Acad Sci U S A 2008, 105:9427-9432

57. Seubert A, Schulein R, Dehio C: Bacterial persistence within erythrocytes: a unique pathogenic strategy of Bartonella spp. Int J Med Microbiol 2002, 291:555-560 